\title{
The Review of Humorous Leader
}

\author{
Juntong Xu \\ School of Management, Jinan University, Guangzhou, China \\ Email:1152436498@qq.com
}

How to cite this paper: Xu, J.T. (2020) The Review of Humorous Leader. Open Journal of Business and Management, 8, 542-551. https://doi.org/10.4236/ojbm.2020.82033

Received: January 28, 2020

Accepted: February 25, 2020

Published: February 28, 2020

Copyright (c) 2020 by author(s) and Scientific Research Publishing Inc. This work is licensed under the Creative Commons Attribution International License (CC BY 4.0).

http://creativecommons.org/licenses/by/4.0/

\begin{abstract}
Nowadays, humor plays an important role in the organization, catching more and more people's attention. Thus, the research about humorous leader is becoming a hot topic. Based on existing researches, we reviewed the concepts and types about humor and humorous leader, and concluded the effects of humorous leaders on subordinates, leaders and organizations. Finally, we concluded with an agenda for future research on humorous leaders.
\end{abstract}

\section{Keywords}

Humorous Leader, Humor Types, Leader-Member Exchange, Innovation Behaviors

\section{Introduction}

With the rapid development of globalization and informatization in the world, enterprises are facing a more competitive environment and a more complex management environment. As an important management role, leaders assume great management responsibility in the survival and development of enterprises, especially in the face of financial tsunami and other crises sweeping the global economic system. In addition to being responsible for the sustainability of the organization, leaders are responsible for motivating team members to perform well. Ho et al. (2011) believed that due to the changes in the macro environment, the previous imperative leadership style believed by enterprise leaders is no longer appropriate [1]. And with the development of positive psychology, people pay more and more attention to mental health problems in the workplace, and the study on humor is one of them. For example, Avolio et al. (1999) showed that humor is an important trait and ability of leaders, and leaders can influence their subordinates by continuously displaying this trait [2]. Decker and Rotondo (2001) believed that humor is an important aspect of the "manager-subordinate" relationship, and the better the use of humor, the better the development of the 
manager-subordinate relationship [3]. Of course, other studies have explored the role of leadership humor in leading innovative behavior and employee creativity. Ho et al. (2011) found in their study that positive humorous leadership positively affects leadership innovation behavior and leadership effectiveness [1]. The research of Tang (2008) also showed that positive humorous leadership contributes to the development of employees' creativity [4].

Thus, it can be seen that there has been a long period of foreign research on the role of humor in leadership. At present, there is a lack of research review on humor in China, which mainly focuses on humor in organizations or workplaces. In view of this, this paper carries out literature review research from the perspective of leaders. Firstly, this paper summarizes the research on the concept and the meaning of humor and humorous leadership, and then discusses the main types of humorous leadership. Then this paper analyzes the influence effect of humorous leadership from the three perspectives of subordinates, leaders and organizations. Finally we look into the future research perspectives of humorous leadership in order to provide some references for the research in this direction.

\section{The Concept of Humor and Humorous Leader}

Different scholars have different views on the concepts of humor. Martineau (1972), for example, gave a simple explanation. He thought any communication case that is seen as witty and humorous can be called humor [5]. Crawford (1994) extended his explanation by including non-verbal and verbal communication, which can generate positive cognitive or emotional responses from the audience [6]. Romero and Cruthirds (2006) combined both perspectives and proposed that humor in organizations includes all interesting communication activities that generate positive emotions and cognitions in individuals, groups or organizations [7]. They also believed that although people's perception of funny things varies in the organization of humorous communication, humor is still interesting to all people involved in humorous communication. Peng et al. (2017), based on previous studies, proposed that humor is a stable personality trait related to emotion [8]. Through sustained behavior patterns and stable life attitudes, humor forms a social skill and coping style in the face of pressure to improve the effect of interpersonal interaction and health level. It can be seen that there are many differences in the understanding of the meaning of humor in the academic circle. The reason is that scholars have different research perspectives and focuses. However, we can also find common ground in these studies. For example, scholars generally believed that humor exists in the communication process. Humor is interesting, which can make people produce positive emotions and positive cognition. Humor is good for mental health and the healthy development of interpersonal communication and so on. Therefore, in combination with the consensus of these researchers, we can make the following definition of humor, that is, humor is a communication activity that can generate positive emotions or positive cognition among communication participants 
and contribute to interpersonal communication and mental health.

With the increase of employees' spiritual needs in enterprises, the role of leaders is changing constantly, and the research on leadership humor behavior is also increasing day by day. Mao et al. (2017) argued that since the 1980s, researchers have been mining their understanding of the characteristics and effects of humor in the workplace, and have regarded humor as a practical management tool conducive to leadership [9]. What's more, because of the positive relationship between humor and leadership effectiveness, a great number of researchers also regard humor as an important leadership trait. Therefore, it can be seen that scholars have been studying the relationship between humor and leadership for some time, and the role of humorous leadership has attracted more and more researchers' attention. In combination with the above explanations on humor, we can define humorous leaders as those who can make subordinates generate positive emotions or positive cognition through communication activities in the workplace and contribute to the development of leader-subordinate relationship and the psychological health of subordinates, namely humorous leaders.

\section{The Type of Humorous Leader}

Many people may have a question: Is humor always good? Martin et al. (2003) argued that in the past, people regarded humor as a reliable and trustworthy personal trait [10]. But with the in-depth study of humor, scholars found that humor is also divided into different styles. Ho et al. (2011) believed that among different types of humor, some may be harmful to physical health or mental health, or even bring harm to themselves or others [1].

In the existing researches on humorous leadership, most researchers adopt the humorous style framework proposed by Martin et al. (2003) to explore the influence of different types of humorous styles adopted by leaders [10]. The framework adopts the way of $2 \times 2$ humor style, namely "to Oneself or to Others", "Beneficial or Detrimental", and the humor style is divided into: "Self-Enhancing Humor", "Affiliative Humor", “Aggressive Humor" and "Self-Defeating Humor". Therefore, the research on humor is no longer a single perspective, but includes different styles and can be reflected in real life. Following the practice of Martin et al. (2003), we will elaborate the type of humorous leadership.

\subsection{Self-Enhancing Humor}

Self-enhancing humor is a positive humor style that benefits itself. People with this style tend to treat their lives with a humorous attitude. When faced with difficulties or pressure, they often use humor to encourage themselves and maintain a positive attitude. This is also known as a self-regulation or coping defense mechanism. In general, self-enhancing humor is positively associated with self-respect, optimism and good mood, and negatively with anxiety and tension. In short, this humorous style is designed to strengthen one's confidence. Although some scholars believe that self-enhancing humor will impress others, 
according to the definition of Martin et al. (2003), self-enhancing humor focuses more on the internal transformation of individuals, which is difficult to be realized by team members in the initial stage [10]. Ho et al. (2011) also give an example to explain self-enhancing humor: a leader often uses the phrase "I am God and I can make everything come true" as a work motto to encourage himself [1]. According to the scale of Martin et al. (2003) [10], we can also give another example: when some people feel depressed at work, they like to recall some humorous and interesting things in the past to cheer themselves up.

\subsection{Affiliative Humor}

Affiliative humor is a positive style of humor that benefits others, which is also spontaneous, witty and non-confrontational. Affiliative humor focuses on social interactions, acting as a lubricant to ease strangeness and tension and add warmth and intimacy to relationships. Like self-enhancing humor, affiliative humor is positively associated with self-respect, optimism, and good mood, while it is negatively associated with anxiety and tension. According to Martin et al. (2003), when people perform well in this type of humor, they tend to appear sociable, outgoing, happy, emotionally stable and considerate [10]. When leaders use this type of humor in the organization, they usually try to reduce the sense of strangeness with their subordinates and narrow the distance between them. They try to unite team members in various ways and establish a positive cooperative atmosphere, so as to motivate team members to work together for the organization's goals. Ho et al. (2011) also gave an example to explain affable humor: a bald manager was accidentally poured over his head with wine by a young junior supervisor during the orientation meeting. Just as the mood was awkward, the manager instantly resolved the embarrassment by patting his supervisor on the shoulder, saying that this would not solve his hair loss problem $[1]$.

\subsection{Aggressive Humor}

Aggressive humor is a negative style of humor that is detrimental to others. This kind of humor is accompanied by ridicule, sarcasm and sarcasm, and debasement of the audience. Its users tend to acquire a sense of superiority. The deeper the harm to the audience, the more satisfied the users will be, that is, they will build their happiness on the pain of others. According to the research of Martin et al. (2003), aggressive humor has a positive relationship with hostility, aggression and tension, but whether it is harmful to one's physical and mental health remains to be studied [10]. Ho et al. (2011) also illustrated with an example: a finance specialist returned to work after recovering from a leg injury, and because he was away from the post for too long, the financial statement made by him was obviously wrong. His boss teased him and asked whether he was unable to think carefully about his work because he had not recovered from the leg injury [1]. Obviously, people with an aggressive humor style will laugh at someone 
for their flaws or for screwing up something.

\subsection{Self-Defeating Humor}

Self-defeating humor is a kind of negative humor style that does not help itself. Its users try to impress others by belittling themselves. It's also a self-denying defense mechanism, using humor to avoid problems. According to the research of Martin et al. (2003), self-defeating humor is positively correlated with depression and anxiety, while negatively correlated with self-esteem, happiness and social support satisfaction [10]. The use of self-defeating humor by a leader in an organization means endorsing and gaining the approval of his subordinates, which may lead to a decrease in subordinates' confidence in the leader. However, some people believe that self-defeating humor can shorten the distance between a leader and his subordinates, and help them to express themselves freely and give out various suggestions, thus promoting communication between superiors and subordinates. Ho et al. (2011) gave an example of this style of humor: a $\mathrm{CEO}$ often joked with his subordinates that the reason for his poor memory was that he liked to sleep on the upper bunk when he was a child and often fell down, which led to his bad brain [1]. Obviously, the CEO talked about some of his own weaknesses through self-derogation, and made his subordinates more accept himself, so as to bring the two sides closer together.

\section{The Effect of Humorous Leader}

As for the influence effect of humorous leader, there have been abundant research results in academia. Considering the universality and multifaceted influence of humorous leader behavior, this paper chooses three perspectives, that is, subordinate members, leaders themselves and organizations, to illustrate the influence of humorous leader.

\subsection{The Influence of Humorous Leaders on Subordinates}

Humorous leaders mainly affect subordinates from several aspects, including subordinates' innovative behavior, work performance, work commitment, organizational commitment, and mental health and so on. Huo et al. (2012) focused on the analysis of the impact of leaders' offensive humor on employees, and empirically found that leaders' aggressive humor positively affected employees' sense of stress, while as an intermediary variable, employees' sense of stress positively affected employees' addictive behaviors, such as Internet addiction, alcohol addiction, and tobacco addiction [11]. Pundt et al. (2015) studied the relationship between leaders' humorous behaviors and employees' innovative behaviors and found that leaders' humorous behaviors often contribute to employees' innovative behaviors, as long as employees realize that they need to be creative and innovative in completing tasks [12]. Kim et al. (2016) explored the influence of different leadership humor styles on subordinates, and found that self-enhancing humor positively affected subordinates' mental health and work 
performance. Similarly, affiliative humor can also promote mental health, but aggressive humor is not conducive to mental health, and the relationship between leaders' humorous behaviors and subordinates' mental health is realized through the mediating effect of social distance [13]. Goswami et al. (2016) hold that leaders' positive humorous behaviors positively affect subordinates' creativity, work involvement and positive emotions. Besides, the relationship between leadership humor and subordinates' positive emotions is also positively moderated transformational leadership [14]. Mao et al. (2017) regarded humor as a lubricant for the relationship between superiors and subordinates, and found that leadership humor positively affected subordinates' perception of transformational leaders, thus promoting the performance of team members, which is moderated by the conflict between leaders and subordinates [9]. Tremblay (2017) divided humor into positive humor and negative humor. The study finds that negative humor has a greater impact on employee's sense of belonging than positive humor, and employee's sense of belonging, as an intermediary variable, has a positive impact on organizational citizenship behavior [15]. The research of Pundt and Venz (2017) shows that the humorous behaviors of leaders positively affect the organizational commitment of employees, whose relationship is negatively moderated by the demands of subordinate organizational structure [16]. Shi et al. (2017) believed that leaders' affiliative humor positively affected employees' creativity, while aggressive humor significantly negatively affected employees' creativity [17].

\subsection{The Influence of Humorous Leader on Leadership}

The influence of humorous leader on leadership mainly includes leadership effectiveness, leader-subordinate exchange relationship and leadership style. Priest and Swain (2002) explored the relationship between humorous leader and leadership effectiveness, suggesting that good leaders tend to exhibit more humorous behaviors, and that leaders who use humorous behaviors tend to be perceived as having higher leadership effectiveness [18]. Hoption et al. (2013) explored the relationship between the humorous style of leadership and transformational leadership, and used personalized care as one of the indicators of transformational leadership. Empirical research shows that when leaders use self-defeating humor, the score of personalized care index is high. But when leaders used offensive humor, they scored lower on measures of personalized care [19]. Wisse and Rietzschel (2014) studied the relationship between self-defeating humor and leader-member exchange (LMX), and found that self-defeating humor of leaders positively affected leader-member exchange, which was positively moderated by subordinate self-derogatory humor [20]. Pundt and Herrmann (2015) studied the relationship between leadership style and leader-subordinate exchange (LMX), and found that there was a positive relationship between affiliative humor and leader-member exchange, but the relationship between aggressive humor and leader-member exchange is negative. 
And the subordinate's recognition of the leader mediated the relationship between affiliative humor and leader-member exchange [12]. Yang et al. (2017) analyzed the influence of leadership humor on the establishment of the relationship between superior and subordinate based on the differences between Chinese and American cultures. They found that the strength of the relationship in Chinese enterprises was lower than that in North American enterprises, and believed that managers of Chinese enterprises carried out less humor because of the influence of Chinese culture [21]. Ho et al. (2011) analyzed the influence of self-enhancing humor and aggressive humor on leadership, and found that self-enhancing humor has a great effect on leadership in the workplace, which can enhance leaders' innovative behaviors and leadership effectiveness [1]. However, Ho et al. (2011) also found that aggressive humor has a small negative impact on the effectiveness of leadership [1].

\subsection{The Impact of Humorous Leader on Organizations}

Humorous leader affects the morale of employees, the connection between team members, communication behavior, cooperation behavior and organizational atmosphere. The research of Holmes and Marra (2006) shows that effective leaders usually make full use of humorous behaviors to have an impact on the organization. For example, humor can boost the morale of all employees, enhance the connection among team members and build a harmonious organizational atmosphere [22]. Romero and Cruthirds (2006) found that different styles of leadership humor have different effects on the organization. Usually positive humor behaviors help reduce tension in the organization, improve leadership, promote teamwork, communication behaviors, creativity, and build a harmonious culture of the organization. In addition, the role of humor in organizations is also influenced by race and gender differences [7]. Tremblay and Gibson (2016) combined leadership styles to analyze the impact of different types of leadership humor on organizations. Their study has shown that the more self-defeating humor used by the less skilled contingent reward leaders will help the development of the organization, while the more skilled contingent reward leaders will help the development of the organization. Besides, the more aggressive humor a Laissez-faire leader uses, the less helpful the organization will be. At the same time, the leadership's aggressive humor behavior is not conducive to the formation and development of civic behavior in the organization [23].

\section{Research Implications and Prospects}

\subsection{Research Implications}

Nowadays, it's obvious that humor can't be ignored in the workplace. More and more scholars focus on the study of humorous leadership, studying its effects and exploring its management value. Existing research shows that leaders using humor in organizations can help employees maintain mental health, generate 
innovative behavior and improve work performance (Pundt et al., 2015 [12]; Kim et al., 2016 [13]). Therefore, in management practice, leaders can continue to use humor to create a relaxed and pleasant working environment, and improve team performance at a lower cost. However, not all humor can have a positive impact on organizations and employees. Leaders should use more constructive humor, such as affiliative humor and self-enhancing humor, and avoid using negative humor. At the same time, leaders should combine their own leadership styles and choose appropriate humorous styles to match each other to maximize the effectiveness of leadership.

\subsection{Research Prospects}

The current research on humorous leader has covered a lot of content, but there is still a research gap for further expansion. Therefore, based on the limitations of current research, this paper puts forward a perspective on the research of humorous leaders.

First, the existing literature mainly discusses the influence of humorous leader on work performance, mental health, leadership effectiveness, organizational atmosphere and other aspects, and most of them will be studied from the perspective of leader-member exchange (LMX). However, most of the current researchers study from the perspective of leaders, ignoring the characteristics of subordinates. Since leader-member exchange (LMX) is an interactive relationship between leaders and subordinate members, in the future research on humorous leaders, the relationship and interaction between different types of leadership humor styles and different types of subordinate humor styles can be analyzed in combination with the subordinate humor styles, and the influence of this matching relationship on subordinate members, leaders themselves, organizational construction and other aspects can be discussed.

Second, the future study should be based on the background of Chinese culture. The existing researches on humorous leader mainly come from abroad, and most of the researches are based on foreign data. Although some scholars have analyzed the differences in the use of humor between Chinese enterprises and North American enterprises, such as Yang et al. (2017) [21]. However, studies on the influence of humorous leaders in Chinese organizations are still lacking. Therefore, in the future research, we can combine China's unique system and traditional culture to develop research tools and methods suitable for China's specific reality, and explore the role of humorous leaders in the context of Chinese culture.

Third, in the process of empirical analysis, the existing researches mainly adopt cross-sectional questionnaire survey data, which may lead to common method bias, thus unable to objectively reveal the causal relationship of the research. Therefore, the future research should carry out longitudinal tracking research, obtain data from multiple sources, and explore the changes of leadership humor in different situations as well as the influence mechanism on organiza- 
tions and subordinates.

\section{Conflicts of Interest}

The author declares no conflicts of interest regarding the publication of this paper.

\section{References}

[1] Ho, L.H., Wang, Y.P., Huang, H.C. and Chen, H.C. (2011) Influence of Humorous Leadership at Workplace on the Innovative Behavior of Leaders and Their Leadership Effectiveness. African Journal of Business Management, 5, 6674-6683.

[2] Avolio, B.J., Howell, J.M. and Sosik, J.J. (1999) A Funny Thing Happened on the Way to the Bottom Line: Humor as a Moderator of Leadership Style Effects. The Academy of Management Journal, 42, 219-227. https://doi.org/10.2307/257094

[3] Decker, W.H. and Rotondo, D.M. (2001) Relationships among Gender, Type of Humor, and Perceived Leader Effectiveness. Journal of Managerial Issues, 13, 450-465.

[4] Tang, Y.T. (2008) The Relationship between Use of Humor by Leaders and R\&D Employee Innovative Behavior: Evidence from Taiwan. Asia Pacific Management Review, 13, 635-653.

[5] Martineau, H. (1972) A Model of the Social Functions of Humor. In: Goldstein, J.H. Ed., The Psychology of Humor. Theoretical Perspectives and Empirical Issues, Academic Press, New York, 101-125. https://doi.org/10.1016/B978-0-12-288950-9.50011-0

[6] Crawford, C.B. (1994) Theory and Implications Regarding the Utilization of Strategic Humor by Leaders. The Journal of Leadership Studies, 4, 53-68. https://doi.org/10.1177/107179199400100406

[7] Romero, E.J. and Cruthirds, K.W. (2006) The Use of Humor in the Workplace. Academy of Management Perspectives, 20, 58-69. https://doi.org/10.5465/amp.2006.20591005

[8] Peng, K. and Li, Y. (2017) Research Review of Organizational Humor. Chinese Journal of Applied Psychology, 23, 376-384.

[9] Mao, J., Chiang, J.T., Zhang, Y., et al. (2017) Humor as a Relationship Lubricant: The Implications of Leader Humor on Transformational Leadership Perceptions and Team Performance. Journal of Leadership \& Organizational Studies, 24, 494-506. https://doi.org/10.1177/1548051817707518

[10] Martin, R.A., Puhlik-Doris, P., Larsen, G., et al. (2003) Individual Differences in Uses of Humor and Their Relation to Psychological Well-Being: Development of the Humor Styles Questionnaire. Journal of Research in Personality, 37, 48-75. https://doi.org/10.1016/S0092-6566(02)00534-2

[11] Huo, Y., Lam, W. and Chen, Z. (2012) Am I the Only One This Supervisor Is Laughing at? Effects of Aggressive Humor on Employee Strain and Addictive Behaviors. Personnel Psychology, 65, 859-885. https://doi.org/10.1111/peps.12004

[12] Pundt, A. and Herrmann, F. (2015) Affiliative and Aggressive Humour in Leadership and Their Relationship to Leader-Member Exchange. Journal of Occupational and Organizational Psychology, 88, 108-125. https://doi.org/10.1111/joop.12081

[13] Kim, T., Lee, D. and Wong, N.Y.S. (2016) Supervisor Humor and Employee Outcomes: The Role of Social Distance and Affective Trust in Supervisor. Journal of 
Business and Psychology, 31, 125-139. https://doi.org/10.1007/s10869-015-9406-9

[14] Goswami, A., Nair, P., Beehr, T., et al. (2016) The Relationship of Leaders' Humor and Employees' Work Engagement Mediated by Positive Emotions Moderating Effect of Leaders' Transformational Leadership Style. Leadership \& Organization Development Journal, 37, 1083-1099. https://doi.org/10.1108/LODJ-01-2015-0001

[15] Tremblay, M. (2017) Humor in Teams: Multilevel Relationships between Humor Climate, Inclusion, Trust, and Citizenship Behaviors. Journal of Business and Psychology, 32, 363-378. https://doi.org/10.1007/s10869-016-9445-x

[16] Pundt, A. and Venz, L. (2017) Personal Need for Structure as a Boundary Condition for Humor in Leadership. Journal of Organizational Behavior, 38, 87-107. https://doi.org/10.1002/job.2112

[17] Shi, G., Mao, S. and Wang, K. (2017) Mechanism of Action of Humorous Leadership on Employee Creativity: From the Perspective of Social Exchange Theory. Human Resource Development in China, No. 11, 17-31.

[18] Priest, R.F. and Swain, J.E. (2002) Humor and Its Implications for Leadership Effectiveness. Humor-International Journal of Humor Research, 15, 169-189. https://doi.org/10.1515/humr.2002.010

[19] Colette, H., Julian, B. and Turner, N. (2013) "It's Not You, It's Me": Transformational Leadership and Self-Deprecating Humor. Leadership \& Organization Development Journal, 34, 4-19. https://doi.org/10.1108/01437731311289947

[20] Wisse, B. and Rietzschel, E. (2014) Humor in Leader-Follower Relationships: Humor Styles, Similarity and Relationship Quality. Humor-International Journal of Humor Research, 27, 249-269. https://doi.org/10.1515/humor-2014-0017

[21] Yang, I., Kitchen, P.J. and Bacouel-Jentjens, S. (2017) How to Promote Relationship-Building Leadership at Work? A Comparative Exploration of Leader Humor Behavior between North America and China. The International Journal of Human Resource, 28, 1421-1454. https://doi.org/10.1080/09585192.2015.1089065

[22] Holmes, J. and Marra, M. (2006) Humor and Leadership Style. Humor-International Journal of Humor Research, 19, 119-138. https://doi.org/10.1515/HUMOR.2006.006

[23] Tremblay, M. and Gibson, M. (2015) The Role of Humor in the Relationship Between Transactional Leadership Behavior, Perceived Supervisor Support, and Citizenship Behavior. Journal of Leadership \& Organizational Studies, 23, 39-54. https://doi.org/10.1177/1548051815613018 